\title{
Uniportal, single incision VATS for the skeptics
}

As surgeons we are living in an amazing era. Rapid advances in technology transform our surgeries in countless ways. After 20 years the first uniportal VATS were performed (1-3), the procedure has its own space in the thoracic surgery (4), and this special issue takes the readers to reflect on the exciting recent development and future expectations of this modern and futuristic surgical approach. Furthermore this special issue has the goal to demonstrate and illuminate the distracted minds and the skeptic about the numerous potentiality of the uniportal-single incision VATS approach.

The reason why we decided to call the special issue uniportal-single incision VATS is not only due to the never-ending dilemma with the definition $(5,6)$, but also to the pragmatic results which can be obtained from PUBMED. Roughly, at April 29, 2018 when the search words were "Uniportal VATS" 389 titles were available, while when the search word was "Single Incision VATS", the papers were 267. We could certainly find other papers if the search words are single port VATS or single trocar VATS. Notably, most of these papers have been published in the last 3 years.

In this day and age the importance of uniportal/single incision VATS is therefore clearly demonstrated not only by the increasing number of operations performed worldwide but also from the increasing number of scientific publications on this subject.

Since the beginning, the purpose of uniportal VATS was to perform operations in an easier way than the classic thoracoscope but with the intent to achieve the same or better clinical results in a less traumatic way than a classic thoracotomy, and leading to an improvement of postoperative pain and early post operatory quality of life. At that time the surgeon (MM) envisaged to overcome some limitations with the reduction of the size of the instruments but more importantly as the author wrote by "the manufacture of specialized instruments by major companies may help to eliminate the disadvantages" (2). This has been done, and the introduction of sophisticated technology such as high-frequency mechanical energy devices together with the surgeon' s spirit permitted in 2010 that uniportal VATS became a reality also for major lung resection $(7,8)$. Although there are not yet prospective long term oncological results, uniportal VATS is an approach which has been demonstrated to be safe to operate lung cancer and not inferior to other approaches (4). Certainly, it is not an approach for everybody but it is an approach which should be performed firstly with caution and respect to obtain the competency to work safely, effectively and in an independent way. Nevertheless, as I wrote previously (9), in the absence of a superiority of one surgical approach over another to treat lung cancer, we should perform major chest operations using the approach (uniportal, biportal or multiportal) that suits us best, as patient safety must remain at the top of our duty list.

After an historical view, world famous anesthesiologists and thoracic surgeons gave their marvelous contributions to the development of this relatively new "exciting" surgical approach in thoracic surgery (10-28).

Some topics have been inevitably addresses as uniportal VATS for lung cancer. But thoracic surgery is not only lung cancer surgery. Several other topics such as uniportal VATS in pneumothorax and empyema has also been presented, and specific chapters have been written. Interestingly, sympathectomy, and thymectomy could be successfully done by uniportal approach through different chest incisions. Moreover although uniportal VATS in esophageal cancer is at the early stage, promising good results have been shown. A perspective vision has also been given by world famous surgeons.

After seeing his surgeon, the modern patient often takes information about the surgeon and the "proposed" operation through the web. The result is that the patients of the third millennium are becoming more and more exigent, and this is the main reason why I believe that the new generation of thoracic surgeons needs to become better surgeons than us. Consequently, this special issue could provide initial in deep information which will be helpful to increase the necessary selfconfidence to perform such skilled operations and to fully understand that the surgeon for the future need to learn to work as a uni-surgeon (10).

I have to thanks all authors of this supplement for reserving their precious time to write such outstanding articles, and last but not the least I would like to thank $70 \mathrm{VS}$ journal for hosting this supplement and the staff members for their outstanding work.

Finally, this volume provides by far the most comprehensive review on uniportal and single incision VATS in thoracic surgery, and it is an honor and privilege to share and divulgate the experiences of so many worldwide outstanding colleagues. 


\section{Acknowledgements}

None.

\section{References}

1. Migliore M, Giuliano R, Deodato G. Video-assisted thoracic surgery through a single port. Thoracic surgery and interdisciplinary symposium on the threshold of the third millennium. An international continuing medical education programme. Naples, Italy, 2000:29-30. Available online: http://xoomer.virgilio.it/naples2000/index1.html

2. Migliore M, Deodato G. Single-trocar technique for minimally-invasive surgery of the chest. Surg Endosc 2001;15:899-901.

3. Migliore M. Efficacy and safety of single-trocar technique for minimally invasive surgery of the chest in the treatment of noncomplex pleural disease. J Thorac Cardiovasc Surg 2003;126:1618-23.

4. Gonzalez-Rivas D, Damico TA, Jiang G, et al. Uniportal video-assisted thoracic surgery: a call for better evidence, not just more evidence. Eur J Cardiothorac Surg 2016;50:416-7.

5. Migliore M, Halazeroglu S, Molins L, et al. Uniportal video-assisted thoracic surgery or single-incision video-assisted thoracic surgery for lung resection: clarifying definitions. Future Oncol 2016;12:5-7.

6. Migliore M, Deodato G. Thoracoscopic surgery, video-thoracoscopic surgery, or VATS: a confusion in definition. Ann Thorac Surg 2000;69:1990-1.

7. Gonzalez D, Delgado M, Paradela M, et al. Uni-incisional video-thoracoscopic left lower lobectomy in an incomplete fissure. Innovations (Phila) 2011;6:45-7.

8. Gonzalez-Rivas D, Fieira E, Mendez L, et al. Single-port video-assisted thoracoscopic anatomic segmentectomy and right upper lobectomy. Eur J Cardiothorac Surg 2012;42:e169-71.

9. Migliore M. Video-assisted thoracic surgery techniques for lung cancer: which is better? Future Oncol 2016;12:1-4.

10. Migliore M. Uniportal video-assisted thoracic surgery, and the uni-surgeon: new words for the contemporary world. J Vis Surg 2018;4:45.

11. Mineo TC, Ambrogi V. A glance at the history of uniportal video-assisted thoracic surgery. J Vis Surg 2017;3:157.

12. Sihoe AD. Proper use of history. J Vis Surg 2017;3:185.

13. Hirai K, Enomoto Y, Usuda J. For which thoracic operation. J Vis Surg 2017;3:103.

14. Augustin F, Schmid T. A word of caution—when uniportal VATS should not be done. J Vis Surg 2018;4:29.

15. Nardini M, Bilancia R, Dunning J. Perspective on uniportal thoracic surgery: where do we stand and what is the future. J Vis Surg 2017;3:164.

16. Zhao ZR, Lau RW, Ng CS. Anaesthesiology for uniportal VATS: double lumen, single lumen and tubeless. J Vis Surg 2017;3:108.

17. Louis SG, Gibson WJ, King CL, et al. Uniportal video-assisted thoracoscopic surgery (VATS) technique is associated with decreased narcotic usage over traditional VATS lobectomy. J Vis Surg 2017;3:117.

18. Zieliński M, Rybak M, Solarczyk-Bombik K, et al. Subxiphoid uniportal VATS thymectomy. J Vis Surg 2017;3:171.

19. Migliore M, Criscione A, Nardini M, et al. Single incision extended video assisted transcervical thymectomy. J Vis Surg 2017;3:154.

20. Migliore M, Palazzolo M, Pennisi M, et al. Extended uniportal bilateral sympathectomy. J Vis Surg 2018;4:27.

21. Sanna S, Bertolaccini L, Brandolini J, et al. Uniportal video-assisted thoracoscopic surgery in hemothorax. J Vis Surg 2017;3:126.

22. Bertolaccini L, Pardolesi A, Brandolini J, et al. Uniportal video-assisted thoracic surgery for pneumothorax and blebs/bullae. J Vis Surg 2017;3:107.

23. Lerut T. Uniportal video-assisted thoracoscopic surgery in esophageal diseases: an introduction. J Vis Surg 2017;3:182.

24. Batirel HF. Uniportal video-assisted thoracic surgery for esophageal cancer. J Vis Surg 2017;3:156.

25. Halezeroğlu S. Advantages and disadvantages of single incision VATS in major anatomical resection for lung cancer J Vis Surg 2017;3:115.

26. Royo-Crespo I, Vieira A, Ugalde PA. Extended uniportal video-assisted thoracic surgery for lung cancer: is it feasible? J Vis Surg 2018;4:57. 
27. Tentzeris V, Papagiannopoulos K Uniportal video-assisted thoracic surgery treatment of intra-operative complications. J Vis Surg 2018;4:74.

28. Mineo TC, Sellitri F, Fabbi E, et al. Uniportal non intubated lung metastasectomy. J Vis Surg 2017;3:118.

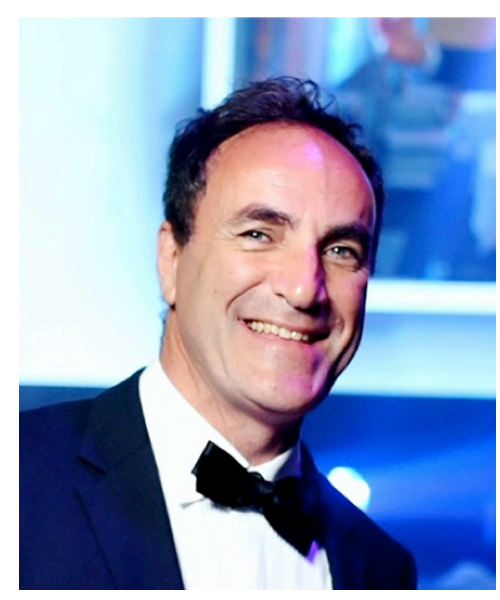

Marcello Migliore.

Marcello Migliore, MD, PhD, FETCS

Section of Thoracic Surgery, Department of Surgery and Medical Specialities, Policlinico University Hospital, University of Catania, Catania, Italy.

(Email: mmiglior@unict.it)

doi: 10.21037 /jovs.2018.05.06

Conflicts of Interest: The author has no conflicts of interest to declare. View this article at: http://dx.doi.org/10.21037/jovs.2018.05.06

doi: 10.21037 /jovs.2018.05.06

Cite this article as: Migliore M. Uniportal, single incision VATS for the skeptics. J Vis Surg 2018;4:97. 